\title{
Consideration of Invasive Fungal Infections in Immunocompetent
}

\section{Hosts}

\author{
Parisa Badiee, ${ }^{1, *}$ and Mehrzad Zare ${ }^{1}$ \\ ${ }^{1}$ Professor Alborzi Clinical Microbiology Research Center, Shiraz University of Medical Sciences, Shiraz, Iran \\ "Corresponding author: Parisa Badiee, Professor Alborzi Clinical Microbiology Research Center, Nemazi Hospital, Zand Ave, Shiraz, Iran. Tel: +98-7116474292, Fax: \\ +98-7116474303, E-mail: badieep@sums.ac.ir
}

Received 2016 December 03; Revised 2017 April 10; Accepted 2017 April 15.

Keywords: Immunocompetent Host, Fungal Infection, Candida, Aspergillus

Invasive fungal infections (IFIs) are life-threatening infections with poor prognosis. Important cells with antifungal host defence are dendritic cells, neutrophils, macrophages, NK cells, CD4 T cell (Th1, Th2, Th9, Th17, and T Reg), and CD8 cells (1). These cells produce cytokines and chemotactic factors and contribute to human fungal protection $(1,2)$. Invasive fungal infections occur in immunocompromised patients or in patients treated with immunosuppressive or chemotherapy drugs $(3,4)$. Severity of infection depends on the mechanisms of pathogenicity of etiologic agents, mechanisms of the host immune system defense against infection, and the site of infection. These infections are uncommon in healthy individuals, yet unfortunately, in the recent years there have been reports about infection in immunocompetent hosts as well $(5,6)$. It is notable that some patients are healthy in the first examination and after diagnosis of fungal infection, upon secondary examination, risk factors for fungal infections are found.

Different mechanisms have been reported in the diagnosis of pathogenic hyphal form of fungi and yeasts $(2,7)$. Anti-fungal response in humans is caused by macrophage phagocytic processes and inflammatory cytokine compounds, and influence various immune cells, and are induced by cell wall antigens (7). Toll-like receptors (TLR) 2 and TLR4 have been involved in the diagnosis of Candida and Aspergillus species. The mechanisms of infection in immunocompetent hosts have been discussed in the literature. Fungi can escape the innate immune system by inducing an anti-inflammatory cytokine profile (8). Antigens in fungal cell wall, including zymosan, phospholipomannan, glucuronoxylomannan and glucoronoxylomannan, and O-linked mannan have been identified as pathogenassociated molecular patterns for TLR2 and TLR4, respectively $(8,9)$. During hyphal formation in Candida albicans, $\beta$-glucans are obscured by outer fungal component and cannot be recognized by dectin-1. This shielding protects these organisms from the immune system. The following strategies to evade from host defence immunity demonstrate that conidia of fungi could bind and enter human epithelial cell lines and remain viable for a long time and germinate and disseminate. Germinated cells limit the induced levels of inflammatory cytokines $(7,8)$. Pigmentation on some fungi, like Aspergillus species, affects virulence by limiting neutrophil activity and complement C3 deposition (10). Candida albicans and Aspergillus fumigatus were shown to have the ability to bind Factor H on their surface and down-regulate the complement system (10).

Early diagnosis and treatment are needed for the management of IFIs in immunocomponent patients. Current diagnostic tools for establishing a diagnosis of an invasive fungal infection include microbiological cultures of biologic fluids and tissue, antigen assay in serum or broncho alveolar lavage for galactomannan and/or (1,3)- $\beta$-glucan, Candida albicans germ tube antibody detection, and polymerase chain reactions to detect fungal DNAs (11). Noninvasive methods like measure of galactomannan, BD glucan, and molecular methods could serve as initial diagnostics $(3,4)$. As the resistant fungal etiologic agents were reported in the literature $(12,13)$, culture (as the gold standard' method) from sterile clinical specimens and detection of susceptibility pattern of etiologic agents are important. Sampling from sterile sites requires invasive procedures, which are not performed in routine treatment.

\section{Conclusion}

In immunocompetent hosts not responsive to antibiotic therapy, differential diagnosis for fungal infections should be considered, especially when infection progresses. Early diagnosis by clinical, radiological and mycological studies is helpful because infection could cause 
morbidity and mortality.

\section{Acknowledgments}

The authors thank Hassan Khajeie, PhD, for editing the language of the text.

\section{References}

1. Jiang S. Immunity against Fungal Infections. Immunol Immunogenet Insights. 2016;8. doi: 10.4137/iii.s38707.

2. Jimenez-Lopez C, Lorenz MC. Fungal immune evasion in a model host-pathogen interaction: Candida albicans versus macrophages. PLoS Pathog. 2013;9(11). e1003741. doi: 10.1371/journal.ppat.1003741. [PubMed: 24278014].

3. Badiee P, Alborzi A, Malekhosseini SA, Nikeghbalian S, Shakiba E. Determining the incidence of aspergillosis after liver transplant. Exp Clin Transplant. 2010;8(3):220-3. [PubMed: 20716040].

4. Badiee P, Kordbacheh P, Alborzi A, Ramzi M, Shakiba E. Molecular detection of invasive aspergillosis in hematologic malignancies. Infection. 2008;36(6):580-4. doi: 10.1007/s15010-008-7385-8. [PubMed: 18854937].

5. Cetinkaya E, Cortuk M, Gul S, Mert A, Boyaci H, Cam E, et al. Simultaneous Chronic Invasive Fungal Infection and Tracheal Fungus Ball Mimicking Cancer in an Immunocompetent Patient. Case Rep Med. 2016;2016:2416452. doi: 10.1155/2016/2416452. [PubMed: 27418930].
6. Mohammadi H, Sadeghi S, Zandi S. Central Nervous System Aspergilloma in an Immunocompetent Patient: A Case Report. Iran J Public Health. 2015;44(6):869-72. [PubMed: 26258101].

7. Dowling JK, Mansell A. Toll-like receptors: the swiss army knife of immunity and vaccine development. Clin Transl Immunology. 2016;5(5). e85. doi: 10.1038/cti.2016.22. [PubMed: 27350884].

8. Kruger T, Luo T, Schmidt H, Shopova I, Kniemeyer O. Challenges and Strategies for Proteome Analysis of the Interaction of Human Pathogenic Fungi with Host Immune Cells. Proteomes. 2015;3(4):46795. doi: 10.3390/proteomes3040467. [PubMed: 28248281].

9. Konstantinovas C, de Oliveira Mendes TA, Vannier-Santos MA, LimaSantos J. Modulation of Human Immune Response by Fungal Biocontrol Agents. Front Microbiol. 2017;8:39. doi: 10.3389/fmicb.2017.00039. [PubMed: 28217107].

10. Chai LY, Netea MG, Vonk AG, Kullberg BJ. Fungal strategies for overcoming host innate immune response. Med Mycol. 2009;47(3):227-36. doi: 10.1080/13693780802209082. [PubMed: 18654922].

11. Lehrnbecher T, Becker K, Groll AH. Current algorithms in fungal diagnosis in the immunocompromised host. Human fungal pathogen identification: Methods and protocols. 2017. p. 67-84.

12. Parisa B, Alborzi A, Shakiba E, Ziyaeyan M, Rasuli M. Molecular Identification and In-Vitro Susceptibility of Candida albicans and C. dubliniensis Isolated from Immu-nocompromised Patients. Iran Red Crescent Med J. 2009;11(4):391-7.

13. Badiee P, Alborzi A, Moeini M, Haddadi P, Farshad S, Japoni A, et al. Antifungal susceptibility of the aspergillus species by Etest and CLSI reference methods. Arch Iran Med. 2012;15(7):429-32. [PubMed: 22724880]. 